\title{
PENGARUH MODEL PEMBELAJARAN KOOPERATIF TIPE THINK PAIR SHARE TERHADAP HASIL BELAJAR FISIKA
}

\author{
Iwan Setiawan ${ }^{1}$, Fahruddin ${ }^{2}$, Muhammad Subhan ${ }^{3}$ \\ Program Studi Pendidikan Fisika STKIP-Bima. \\ Jl. Piere Tendean Kel. Mande Tel. Fax (0374) 42801, Bima 84191, Indonesia. \\ Email: : iwan.setiawanphysicd@gmail.com \\ bangfenmbozo@gmail.com \\ d.hans2102@gmail.com
}

\begin{abstract}
ABSTRAK : Penelitian ini bertujuan untuk mengetahui pengaruh model pembelajaran kooperatif tipe Think Pair Share (TPS) terhadap hasil belajar fisika siswa kelas XI IPA SMA Negeri 1 Ambalawi tahun ajaran 2018/2019 dengan jenis penelitian ini adalah penelitian kuantitatif dengan metode kuasi eksperimen dan menggunakan desain Control Group Pretest-Posttest. Sampel dalam penelitian ini adalah kelas XI IPA 1 sebagai kelas eksperimen dan XI IPA 2 sebagai kelas kontrol. Instrumen yang digunakan dalam penelitian ini adalah instrumen tes hasil belajar dan untuk menganalisis data menggunakan uji hipotesis dan uji $\mathrm{N}$-gain.Hasil analisis data menunjukkan bahwa diperoleh uji hipotesis (Uji-t independent) $t_{\text {hitung }}=8,560$ dibandingkan $t_{\text {tabel }}=1,998$. Kriteria pengujian $\mathrm{H}_{\mathrm{a}}$ diterima karena $\mathrm{t}_{\text {hitung }}>\mathrm{t}$ tabel . Uji $\mathrm{N}$-gain menunjukkan bahwa dari 33 orang jumlah keseluruhan siswa mendapatkan pengaruh dari model pembelajaran kooperatif tipe think pair share kategori tinggi yaitu sebesar 45,45\% atau 15 orang siswa, kemudian sebesar 30,30\% atau 10 orang siswa mendapatkan pengaruh kategori sedang, dan sebesar $24,24 \%$ atau 8 orang siswa mendapatkan penagruh kategori rendah. Dengan demikian dapat ditarik kesimpulan bahwa terdapat pengaruh model pembelajaran kooperatif tipe think pair share (TPS) terhadap hasil belajar fisika siswa kelas XI IPA SMA Negeri 1 Ambalawi tahun ajaran 2018/2019.
\end{abstract}

Kata kunci: Tipe Think Pair Share, Hasil Belajar

\section{PENDAHULUAN}

Pendidikan dapat diartikan dari berbagai sudut pandang yaitu pendidikan berwujud sebagai suatu sistem, pendidikan berwujud sebagai suatu proses, dan pendidikan berwujud sebagai suatu hasil. Pendidikan berwujud sebagai suatu sistem maksudnya adalah pendidikan dipandang sebagai keseluruhan gagasan terpadu yang mengatur usaha-usaha sadar untuk membina seseorang mencapai harkat kemanusiaannya secara utuh. Pendidikan berwujud sebagai suatu proses adalah dipandang sebagai pelaksana usaha-usaha untuk mencapai tujuan tertentu dalam rangka mencapai harkat kemanusiaan seseorang secara utuh dan pendidikan berwujud sebagai suatu hasil, artinya pendidikan dipandang sebagai sesuatu yang telah dicapai atau dimiliki seseorang setelah proses pendidikan berlangsung [1].

Dalam proses pembelajaran tidak akan selalu efektif, mengingat setiap siswa mempunyai taraf berfikir yang berbeda dan adanya kesulitan siswa dalam memecahkan suatu masalah, maka dengan keterampilan dan keahlian yang dimiliki seorang guru diharapkan mampu memilih model pembelajaran yang tepat agar siswa menguasai pelajaran sesuai dengan target yang akan dicapai dalam kurikulum.

Salah satu masalah yang dihadapi oleh siswa dalam proses belajar mengajar yaitu kesulitan siswa dalam memahami materi yang di ajarkan guru dengan menggunakan model pembelajaran yang belum mengaktifkan seluruh siswa. Selama ini guru masih menggunakan model pembelajaran kelompok yang konvensional. Model pembelajaran seperti ini menyebabkan keterlibatan seluruh siswa dalam aktivitas pembelajaran yang sangat kecil, karena kegiatan pembelajaran di dominasi oleh siswa yang memiliki kemampuan tinggi sementara yang memiliki kemampuan rendah hanya menonton saja (pasif). Hal ini berarti dalam suatu kelompok belajar masih banyak siswa yang belum melakukan keterampilan kooperatif. Hal ini menyebabkan sebagian besar siswa terutama yang memiliki kemampuan rendah enggan berpikir, sehingga timbul perasaan jenuh dan bosan dalam mengikuti pelajaran fisika. Akibat dari sikap siswa tersebut, maka hasil belajarpun kurang memuaskan, dalam arti tidak memenuhi batas tuntas yang di tetapkan sekolah.

Dalam proses belajar mengajar melibatkan berbagai macam aktivitas yang harus dilakukan, terutama jika menginginkan hasil yang optimal. Salah satu cara yang dapat dipakai agar mendapatkan hasil yang optimal seperti yang diinginkan adalah memberi tekanan dalam proses pembelajaran. Hal ini dapat dilaksanakan dengan memilih salah satu model pembelajaran yang tepat karena pemilihan model 
pembelajaran yang tepat pada hakikatnya merupakan salah satu upaya dalam mengoptimalkan hasil belajar siswa.

Salah satu upaya untuk meningkatkan mutu pembelajaran tersebut yaitu dengan melakukan perbaikan pada proses pembelajaran di kelas dengan model pembelajaran berpusat pada siswa atau bergeser kepada prinsip Student-Centered-Learning (SCL), dengan menfokuskan pada tercapainya kompetensi siswa yang bermandiri dan berkompeten. Hal ini berarti mahasiswa harus didorong untuk memiliki motivasi dalam diri mereka sendiri, kemudian berupaya untuk mencapai hasil belajar yang diinginkan. Adapun kondisi riil siswa yang ada di SMAN 1 Ambalawi kabupaten Bima antara lain: a) siswa yang memiliki kemampuan akademik yang berbeda dengan dilatar belakangi sekolah yang berbeda , b) siswa yang berasal dari desa/daerah asal yang berbeda-beda, c) banyaknya jumlah siswa pada tiap kelas, d) banyaknya jenis kelamin perempuan pada tiap kelas. Dari keadaan yang heterogen itu maka perlu dikembangkan suatu model pembelajaran yang dapat mengorganisasikan siswa untuk bekerja dan belajar kelompok, sehingga dapat menerapkan komunikasi interpersonal serta keterlibatan kelompok diantara peserta didik. Salah satu model pembelajaran yang relevan sesuai dengan keadaan siswa di atas yaitu dengan menerapkan model pembelajaran kooperatif [2].

Model pembelajaran kooperatif dapat memotivasi siswa, memanfaatkan seluruh energi sosial siswa, saling mengambil tanggung jawab. Model pembelajaran kooperatif membantu siswa belajar mulai dari keterampilan dasar sampai pemecahan masalah yang kompleks. Model Pembelajaran kooperatif memiliki beberapa tipe. Salah satu tipe model pembelajaran kooperatif yang dapat membangun kepercayaan diri siswa dan mendorong partisipasi mereka dalam kelas adalah model pembelajaran kooperatif tipe Think-PairShare. Model Pembelajaran kooperatif tipe Think-PairShare membantu siswa mengintepretasikan ide mereka bersama dan memperbaiki pemahaman [3]. Dalam hal ini, guru sangat berperan penting untuk membimbing siswa melakukan diskusi, sehingga terciptanya suasana belajar yang lebih hidup, aktif, kreatif, efektif dan menyenangkan. Dengan demikian jelas bahwa melalui model pembelajaran Think-Pair-Share, siswa secara langsung dapat memecahkan masalah, memahami suatu materi secara berkelompok dan saling membantu antara satu dengan yang lainnya, membuat kesimpulan (diskusi) serta mempresentasikan di depan kelas sebagai salah satu langkah evaluasi terhadap kegiatan pembelajaran yang telah dilakukan. Hal ini menunjukkan bahwa penggunaan model pembelajaran Think-Pair-Share sebagai salah satu upaya dalam meningkatkan prestasi belajar siswa. Model pembelajaran kooperatif tipe Think-Pair-Share cocok digunakan di SMA karena kondisi siswa SMA yang masih dalam masa remaja membuat mereka menyukai hal baru dan lebih terbuka dengan teman sebaya dalam memecahkan permasalahan yang mereka hadapi.

\section{METODE PENELITIAN}

Jenis penelitian ini adalah penelitian kuantitatif karena data penelitian berupa angka-angka dan analisis menggunakan statistik. Penelitian ini menggunakan metode eksperimen semu atau quasi eksperiment yaitu metode metode penelitian yang melakukan pengontrolan terhadap salah satu variabel yang ada [4].

Desain atau rancangan penelitian yang digunakan adalah Control Group Pretest-Posttest. Dalam desain ini terdapat dua sampel kelompok yang dipilih secara random yaitu kelompok eksperimen dan kelompok kontrol, kedua kelompok tersebut diberi tes awal (pretes) dengan tes yang sama, kemudian hasil pretes diuji perbedaannya. Kelompok eksperimen diterapkan model pembelajaran kooperatif tipe think pair share (TPS) dan kelompok kontrol diterapkan model pembelajaran konvensional/ceramah. Setelah diberikan perlakuan, kedua kelompok tersebut diberi tes akhir (posttes) dengan tes yang sama, kemudian hasil posttes diuji perbedaannya. Perbedaaan yang berarti antara hasil tes awal dan tes akhir pada kelompok eksperimen serta perbedaan hasil tes akhir antara kelompok eksperimen dan kontrol menunjukan pengaruh dari perlakuan yang diberikan.

Tabel 1. Desain Evaluasi Penelitian

\begin{tabular}{lccc}
\hline Kelompok & $\begin{array}{c}\text { Pre } \\
\text { Test }\end{array}$ & $\begin{array}{c}\text { Treatment } \\
\text { (Variabel Bebas) }\end{array}$ & $\begin{array}{c}\text { Post } \\
\text { Test }\end{array}$ \\
\hline Eksperimen & $\mathrm{T}_{1}$ & $\mathrm{X}_{1}$ & $\mathrm{~T}_{2}$ \\
Kontrol & $\mathrm{T}_{1}$ & $\mathrm{X}_{2}$ & $\mathrm{~T}_{2}$ \\
\hline
\end{tabular}

Sampel penelitian ini diambil pada kelas XI IPA I dan kelas XI IPA II SMA Negeri 1 Ambalawi Tahun pelajaran 2018/2019.

Untuk mendapatkan data yang berkualitas, maka perlu digunakan instrumen penelitian yang benar-benar dapat mengukur hasil belajar. Pengukuran hasil belajar dalam peneltian ini hanya meneliti aspek kognitif saja sehingga yang dipakai untuk instrumennya adalah tes berupa soal obyektif yang diberikan kepada masingmasing kelas sampel. Setiap soal dilengkapi dengan empat alternatif pilihan jawaban dengan penskoran tes 
jawaban benar diberi skor 1 dan yang salah diberi skor 0 .

\section{A. Pengujian Instrumen Penelitian}

\section{Uji Validitas}

Untuk mengatur validitas item, menggunakan persamaan korelasi "product moment" adalah sebagai berikut :

$$
r_{x y}=\frac{N \cdot \sum x y-\sum x \cdot \sum y}{\left.\sqrt{\left(N \cdot \sum x^{2}\right.}-\left(\sum x\right)^{2}\right) \cdot\left(N \cdot \sum y^{2}-\left(\sum y\right)^{2}\right)}
$$

2. Uji Reliabilitas

Reliabilitas instrumen yang digunakan adalah "Koefisien Alpha" pengujian tingkat reliabilitas" yaitu :

$$
r_{i i}=\frac{k}{k-1}\left[1-\frac{\sum s_{i}^{2}}{s_{t}^{2}}\right]
$$

Dengan $S^{2}$ : Varians total

$$
s^{2}=\Sigma x^{2}-\frac{\left(\frac{(\Sigma x)^{2}}{N}\right)}{N}
$$

\section{B. Teknik Analisis Data}

\section{Uji Normalitas}

Uji normalitas data ini dilakukan untuk mengetahui apakah sebaran data kelompok eksperimen dan kelompok kontrol berdistribusi normal atau tidak. Untuk menguji normalitas dalam penelitian ini menggunakan rumus "Liliefort" sebagai berikut :

$$
Z_{i}=\frac{y_{i}-\bar{y}}{s}
$$

Hasil uji normalitas akan diterima jika $X_{\text {Hitung }}^{2}<X_{\text {Hitung }}^{2}$ begitupun sebaliknya dengan taraf signifikan $\alpha=0,05$ dan dengan derajat kebebasan $(\mathrm{dk})=\mathrm{k}-1$.

\section{Uji Homogenitas}

Uji homogenitas dilakukan untuk mengetahui apakah kedua data pada kelas eksperimen dan kelas kontrol tersebut homogen atau tidak. Statistik yang digunakan untuk uji homogenitas sampel adalah uji homogenitas varians dengan langkah- langkah sebagai berikut :

a. Mencari nilai varians terbesar dan varians terkecil dengan rumus :

$$
S^{2}=\sqrt{\frac{n \cdot \Sigma X^{2}-(\Sigma X)^{2}}{n(n-1)}}
$$

b. Membandingkan nilai dengan dengan rumus dk pembilang $=$ (untuk varians terbesar) $\mathrm{dk}$ penyebut $=$ (untuk varians terkecil).

Dengan rumus:

$$
\mathrm{F}=\frac{s_{1}^{n}}{s_{2}^{2}}
$$

Adapun kriteria pengujiannya sebagai berikut :
Jika $\mathrm{F}_{\text {hitung }}<\mathrm{F}_{\text {tabel }}$ maka data memiliki varian homogen jika $F_{\text {hitung }}>F_{\text {tabel }}$ maka data tidak memiliki varian homogen

\section{Uji Hipotesis}

Setelah uji prasyarat dilakukan dan data yang dinyataan berdistribusi normal dan homogen, maka dilakukan analisis data untuk mengetahui pengaruh model pembelajaran kooperatif tipe think pair share terhadap hasil belajar fisika siswa yang diukur dengan pengujian hipotesis. Teknik yang digunakan untuk menguji hipotesis dalam penelitian ini adalah menggunakan rumus Polled Varians yaitu menguji perbedaan dua rata-rata dari kelompok eksperimen dan kelompok kontrol. Adapun rumus uji t sebagai berikut :

$$
t=\frac{\bar{X}_{1}-\bar{X}_{2}}{\sqrt{\frac{\left(n_{1}-1\right) S_{1}^{2}+\left(n_{2}-1\right) S_{2}^{2}}{n_{1}+n_{2}-2}\left(\frac{1}{n_{1}}+\frac{1}{n_{2}}\right)}}
$$

\section{Uji N- Gain}

Dalam penelitian ini menggunakan data hasil pretest dan posttest, sehingga untuk menganalisis data diperlukan uji N-Gain untuk mengetahui selisih presentase hasil pretest dengan posttest kelas eksperimen. Adapun rumus yang digunakan sebagai berikut :

$$
N-\text { Gain }=\frac{S_{\text {post }}-S_{\text {pre }}}{S_{\text {Max }}-S_{\text {pre }}}
$$

\section{HASIL DAN PEMBAHASAN}

1. Hasil uji Validitas

Instrumen yang digunakan untuk pretest dan posttest terlebih dahulu divalidasi yang diberikan kepada 20 siswa yang ada di SMA Negeri 1 Ambalawi yaitu kelas XII IPA 1. korelasi "Product Moment" dengan $r_{\text {tabel }}=0,3783$. Dari keterangan yang sudah dicantumkan pada tabel di atas menunjukkan bahwa 15 nomor soal yang diujikan, terdapat 9 nomor soal yang memenuhi kriteria valid dan bisa dijadikan instrumen dalam pretest maupun posttest.

\section{Uji Reliabilitas}

Data yang memenuhi kriteria valid kemudian diuji reliabilitaskan, dengan tujuan melihat ketetapan instrumen evaluasi atau ketetapan siswa dalam menjawab instrumen evaluasi tersebut. Setelah dilakukan perhitungan diperoleh $\mathrm{r}_{\text {hitung }}$ sebesar 0,684234 kemudian dikonsultasikan pada $r_{\text {tabel }}$ product moment pada taraf signifikansi 0,05 dengan $\mathrm{N}=20$ siswa adalah 0,3598 . Dengan demikian $r_{\text {hitung }}>r_{\text {tabel }}$ yaitu $0,684234>$ 0,3598 maka soalnya reliabel.

[6]. A. Uji Prasyarat Hipotesis

1. Uji Normalitas 
Uji normalitas pada penelitian ini menggunakan persamaan liliefort berdasarkan data posttest kelas eksperimen maupun kelas kontrol, diperoleh data sebagai berikut :

Tabel 2. Data hasil Uji Normalitas Liliefort

\begin{tabular}{cccc}
\hline \multicolumn{2}{c}{ Kelompok $\mathrm{L}_{\text {hitung }}$} & $\mathrm{L}_{\text {tabel }}$ & Ket. \\
\hline Eksp & 0,129484 & 0,154233 & Normal \\
Kontr & 0,101249 & 0,151948 & Normal \\
\hline
\end{tabular}

Pada tabel uji normalitas menunjukan bahwa data kelompok eksperimen dan data kelompok kontrol mempunyai nilai varians yang memenuhi kriteria yaitu $L_{\text {hitung }}<L_{\text {tabel. }}$. Dari pernyataan tersebut dapat ditarik kesimpulan bahwa data kedua kelompok yang diteliti tersebut berdistribusi normal, sehingga data kelompok eksperimen dan kelompok kontrol tersebut telah memenuhi salah satu syarat untuk melakukan analisis uji hipotesis.

\section{Uji Homogenitas}

Pengujian homogenitas dalalm penelitian ini menggunakan uji homogenitas varian, hasil analisis pegujian homogenitas dapat dilihat pada tabel di bawah ini :

Tabel 3. Data hasil Uji Homogenitas

\begin{tabular}{|c|c|c|c|c|c|c|}
\hline$\alpha$ & Kelas & Jml. & $\sqrt{s^{2}}$ & $\mathrm{~F}_{\text {hitung }}$ & $\mathrm{F}_{\text {tabel }}$ & Ket. \\
\hline \multirow{2}{*}{0,05} & Eks & 33 & 137,79 & \multirow{2}{*}{1,385} & \multirow{2}{*}{1,799} & \multirow{2}{*}{ Homogen } \\
\hline & Kontr & 34 & 99,51 & & & \\
\hline
\end{tabular}

Pada tabel di atas diperoleh nilai $\mathrm{F}_{\text {hitung }}<\mathrm{F}_{\text {tabel }}$ yaitu $1,3848<1,799$. Dari analisis yang dilakukan dapat ditarik kesimpulan bahwa data yang dijadikan sebagai sampel dalam penelitian ini memenuhi kriteria homogen, sehingga dapat dianalisis menggunakan statistik parametriks.

\section{Uji Hipotesis}

Pengujian hipotesis dilakukan untuk melihat seberapa besar pengaruh model pembelajaran pembelajaran kooperatif tipe think pair share (TPS) yang dilihat dari hasil belajar fisika siswa pada sampel yang telah diberikan tindakan. Ada pun data hasil uji t independent tersebut adalah sebagai berikut :

Tabel 4. Uji Hipotesis t independent

\begin{tabular}{lccccc}
\hline Kela & $\overline{x_{1}}$ Postte & $\overline{x_{2}}$ Prete & $x_{1}-x_{2}$ & $\mathrm{t}_{\text {hitung }}$ & $\mathrm{t}_{\text {tabel }}$ \\
$\mathrm{s}$ & st & st & & & \\
\hline Eksp & 82,333 & 57,121 & 25,212 & 8,56 & 1,99 \\
& & & & 0 & 8 \\
\hline
\end{tabular}

Berdasarkan perhitungan di atas diperoleh $t_{\text {hitung }}$ $=8,560$ dengan taraf signifikan 0,05 dan derajat kebebasan $(\mathrm{dk})=\mathrm{n}_{1}+\mathrm{n}_{2}-2=64$ sehingga diperoleh $\mathrm{t}$ tabel $=1,998$. Sehingga diperoleh $t_{\text {hitung }}>t_{\text {tabel }}$ yaitu 8,560
> 1,998 artinya hipotesis $\left(\mathrm{H}_{\mathrm{a}}\right)$ yang diajukan dapat diterima.

3. Data hasil Uji N-Gain

Dalam penelitian ini menggunakan data hasil pretest dan posttest, sehingga untuk menganalisis data diperlukan uji N-Gain untuk mengetahui selisih hasil pretest dengan posttest kelas yang diteliti. Adapun hasil analisis berdasarkan data yang diperoleh adalah sebagai berikut.

Tabel 5. Data hasil Uji N-Gain

\begin{tabular}{ccccc}
\hline No & $\begin{array}{c}\text { Jml. } \\
\text { Siswa }\end{array}$ & $\%$ & Kriteria N-Gain & Ket. \\
\hline 1 & 15 & $45,45 \%$ & N-Gain $>0,70$ & Tinggi \\
2 & 10 & $30,30 \%$ & $0,30 \leq$ N-Gain $\leq$ & Sedang \\
3 & 8 & $24,24 \%$ & N-Gain $<0,30$ & Rendah \\
\hline
\end{tabular}

Tabel di atas menunjukkan bahwa dari 33 orang jumlah keseluruhan siswa mendapatkan pengaruh dari model pembelajaran kooperatif tipe think pair share kategori tinggi yaitu sebesar $45,45 \%$ atau 15 orang siswa, kemudian sebesar $30,30 \%$ atau 10 orang siswa mendapatkan pengaruh kategori sedang, dan sebesar $24,24 \%$ atau 8 orang siswa mendapatkan penagruh kategori rendah.

Dengan demikian dapat disimpulkan bahwa model pembelajaran kooperatif tipe think pair share memiliki pengaruh besar terhadap hasil belajar siswa kelas XI IPA di SMA Negeri 1 Ambalawi.

\section{KESIMPULAN}

Berdasarkan hasil analisis perhitungan uji hipotesis dan uji $\mathrm{N}$-gain diperoleh hasil sebagai berikut :

1. Hasil uji hipotesis menggunakan komparasi independent diperoleh $t_{\text {hitung }}=8,560>t_{\text {tabel }}=1,998$ pada taraf signifikan $(\alpha)=0,05$ dengan derajat kebebasan 6 .

2. Hasil uji N-gain diperoleh Tabel di atas menunjukkan bahwa dari 33 orang jumlah keseluruhan siswa mendapatkan pengaruh dari model pembelajaran kooperatif tipe think pair share kategori tinggi yaitu sebesar $45,45 \%$ atau 15 orang siswa, kemudian sebesar $30,30 \%$ atau 10 orang siswa mendapatkan pengaruh kategori sedang, dan sebesar $24,24 \%$ atau 8 orang siswa mendapatkan penagruh kategori rendah.

Dengan demikian dapat ditarik kesimpulan bahwa terdapat pengaruh model pembelajaran kooperatif tipe think pair share terhadap hasil belajar fisika siswa kelas XI IPA SMA Negeri 1 Ambalawi tahun ajaran 2018/2019. 


\section{DAFTAR PUSTAKA}

[1] Budiningsih. (2012). Belajar dan Pembelajaran. Yogyakarta: Rineka Cipta

[2] Fahruddin. (2014). Pengaruh Model Pembelajaran kooperatif terhadap hasil belajar kognitif ditinjau dari Kemampuan akademik mahasiswa. Jurnal Euradio Vol.2.no.1. 2014. UNBRA. Down load 15-5-2018.

[3] Kunandar. 2007. Guru Profesional Implementasi Kurikulum Tingkat Satuan Pendidikan (KTSP) dan Sukses dalam Sertifikasi Guru. Jakarta : Raja Grafindo Persada.

[4] Arikunto, S. (2010). Prosedur Penelitian/ Suatu Pendekatan Praktik. Jakarta : Rineka Cipta

[5] Arikunto, S. (2010). Dasar-Dasar Evaluasi Pendidikan (Edisi Revisi). Jakarta: Bumi Aksara.

[6] Sudjana, N. (2009). Penilaian Hasil Proses Belajar Mengajar. Bandung: Remaja Rosdakarya

[7] Sugiyono. (2012). Metode Penelitian Pendidikan (Pendekatan Kuantitatif dan $R \& D$ ). Bandung: Alfabeta

[8] Budi Susetyo. (2010). Statistika untuk analisis data penelitian. Bandung: PT. Refika Aditama 